\title{
Multi-State Analysis of the Impact of Childhood Starvation on the Healthy Life Expectancy of the Elderly in China
}

\author{
Huiling Dong ${ }^{1}$, Bingyi $\mathrm{Wu}^{2}$, Qunhong $\mathrm{Wu}^{3}$
}

[Abstract] Background: Child malnutrition is not only common in developing countries, but also an important issue faced by developed countries. This study aimed to explore the influence and degree of childhood starvation on the health of the elderly population, which providing a reference for formulating health-related policies under the concept of full-life cycle health. Methods: Based on CLHLS longitudinal data in 2008, 2011 and 2014, this paper took a total of 13,185 elderly people aged 65-99 years as the target population. By IMaCH software, with age, gender, and income level as the control variables, and the healthy life expectancy of the elderly in China was measured. The $x^{2}$ test was used to explore the differences in socio-economic status of elderly people with or without starvation in childhood. The paired $t$ test was used to analyze the difference both of healthy life expectancy and healthy life expectancy proportion accounted for remaining life. Results: (1) Transition probabilities in health-disability, health-death and disability-death $(\mathrm{P}<0.05)$ all showed an upward trend with age, where the elderly who experienced starvation in childhood were higher than those without such an experience. However, the probability of disability-health recovery showed a downward trend with age, whereas the elderly who experienced starvation in childhood were lower than those without starvation $(\mathrm{P}<0.05)$. (2) For the elderly who experienced starvation in childhood, the health indicators of the average life expectancy, healthy life expectancy, and healthy life expectancy proportion accounted for the remaining life were lower than those of the elderly without childhood starvation $(\mathrm{P}<0.05)$.Conclusions: The negative impact of childhood starvation on health through the life course till old age, has a persistent negative cumulative effect on the quantity and quality of life for the elderly population; Therefore, it is important to pay attention to the nutritional status of

\footnotetext{
Correspondence: wuby369@163.com

${ }^{1}$ Department of Public Health, Weifang Medical University, No. 7166 Baotong West Street, 261053 Weifang, Shandong, China.
}

Full list of author information is available at the end of the article 
children in poor families from the perspective of social policy-making.

Keywords The Elderly; Healthy Life Expectancy; Childhood Starvation; Life Course

\section{Background}

Since the 1900s, China have entered a violently turbulent modern society. During this period, people's lives were generally difficult, and hunger caused a large number of deaths. After the establishment of the People's Republic of China in 1949, the country experienced a "three-year difficult period" from 1959 to 1961, which caused a nationwide "famine". The number of deaths caused by starvation had risen, and the lack of nutrition greatly affected the health of the population. In recent years, some studies analyzed the impact of the "Great Famine" in childhood on the health and economic status of their adulthood, and found that infants and children who have grown up in the period had shorter life longevity and poorer health and economic status in old age ${ }^{[1]}$. The factors show that the health status of the elderly is not only affected by elements of the old stage, but also earlier life experiences especially childhood.

Life course theory has gradually become an important paradigm for the study of elderly health, emphasizing the long-term impact of life events in critical periods on the health outcomes of elderly. Existing research ${ }^{[2]}$ show that childhood is a critical period of growth and development. At this time, negative nutrition and health shocks experienced may change the original development track of the individual and thus affect the health trajectory of their entire life course. The elderly who experienced starvation during childhood as a health disadvantaged group, have current disadvantages that may depend on the previous unfavorable socioeconomic status. From a policy perspective, it is necessary to understand the long-term effects of malnutrition in earlier life, because child malnutrition is not only common in developing countries, but also an important issue faced by developed countries. Data show that there are approximately 1 billion people in the world who are malnourished, including 140 million preschool children under the age of 5, which will lead to permanent damage to their physical and cognitive development and even death due to nutritional diseases ${ }^{[3]}$. 
In recent years, the economics has begun to pay attention to the long-term effects of life experiences in the fetus or early childhood on health, education and labor market conditions, especially the health and nutritional status before the age of $5^{[4]}$. These studies generally used negative external shocks as an identification event, such as war, famine, flu, etc ${ }^{[5-6]}$. Schellenberg $J$ A, Victora $C$ G and other studies of low-income or middle-income countries such as Brazil, India, and South Africa have found that malnourished children had shorter height in adulthood, fewer years of education, and diminished labor productivity ${ }^{[7]}$.Epidemiology and health economics in China are increasingly concerned about the impact of childhood health and developmental status on their health in adult period. Scholars such as Chen and Zhou ${ }^{[8]}$ analyzed the long-term effects of China's "Great Famine" on the health of those who experienced famine. Studies found that babies and children born or raised during this period had a lower height, poorer health and economic status in adulthood.

In summary, the above-mentioned studies have paid more attention to the lasting impact of severe nutrition and health shocks on the health of economically active people. In most previous research literature, self-assessed health status of the elderly was used as the dependent variable, by which body function of the elderly cannot be reflected effectively due to stronger subjectivity. As for the measurement of healthy life expectancy, most international literature adopts the multi-state life table method, which can reflect the true health level of the study population ${ }^{[9-10]}$. Therefore, based on strict cohort data, this paper takes life course theory as the analysis framework, whether to have the childhood starvation as independent variables, to measure healthy life expectancy of the elderly in China, trying to give answer to the question: to what extent does the accumulated disadvantage formed by childhood starvation affect the health of the elderly?

\section{Data and methods}

\section{Research data}

The data come from Chinese Longitudinal Healthy Longevity Survey (CLHLS). This research project has conducted surveys for 8 times in 23 provinces in China. This study used baseline data of 2008, follow-up 2011 and 2014, with a total of 13,185 people aged 65-99 years as samples. Since the survey did not select samples with equal probability, it was necessary to weigh the samples according to the actual composition of age, gender and residence in the 23 provinces to represent the general 
population of the elderly in the country. Therefore, before calculating the relevant indicators, the paper weighed the data according to the weight coefficients provided by the project team, after which the sample size was 16,200 people.

\section{Variables setting}

The explained variable in this article is the health status of the elderly. The CLHLS database uses the ADL to determine the health status of the elderly. The scale includes 6 measurement items for eating, dressing, indoor activities, going to the toilet, bathing, and controlling toilet. For the above 6 measurement items, if the research subjects select "can be completed", they are judged as "healthy"; if any one of the items is selected as "unable to complete", the sample is judged as "disabled" ${ }^{[11]}$.The core explanatory variable of this article is "Did you experience starvation in childhood", to which the answer is "yes or no". In the questionnaire of CLHLS, the exact age at which starvation occurred is not asked. Therefore, this article draws on the definition of children's physiological age in the Medicine, Education and Labor Legislation field and defines childhood age from 0-12 years old ${ }^{[12-13]}$.

\section{Preparation and calculation of multi-state life table}

IMaCh software is used for the estimation of healthy life expectancy in this study, which is an abbreviation of Interpolated Markov Chain and one of the first batch of software to provide multi-state life table estimation. Its main advantage is the direct use of the original survey data, and the use of multi-period ( $\geq 2$ times) different longitudinal data at intervals, in which processing different health status is considered such as improvement, reduction, no change and death. In this study, State1 and State2 are healthy and disabled respectively, and State 3 is dead ${ }^{[14]}$.

In the multi-state life table, the initial state of the cohort (2008) is "healthy" and "unhealthy"; the end state (2014) is "healthy", "unhealthy" and "death". Each state at the beginning of the period can be transited to any state at the end of the period. In this paper, "whether childhood is Starving" is defined as a binary variable, and "gender" and "income level" are included as control variables to calculate the multi-state healthy life expectancy of the elderly with or without starvation in childhood. The calculation formula of the main variables is as follows (Lievre, A, 2003): 
(1) Let $\mathrm{X}(\mathrm{x})$ denote the state of an individual aged $\mathrm{x}$. After time $\mathrm{h}$ this individual is in state $\mathrm{X}(\mathrm{x}+\mathrm{h})$. Assume that $\mathrm{X}(\mathrm{x})$ is a non-homogeneous discrete parameter Markov chain on these three states with transition probabilities:

$$
{ }_{h} p_{x}^{j k}=\operatorname{Pr}(X(x+h)=k / X(x)=j)
$$

(2) If this individual is observed only once more at timet $t_{3}$, and noted to be in state $l$, then a further contribution to the likelihood is $\left({ }_{d 2} p_{x 2}^{k l}\right)$. In this case the component of the total likelihood due to individual $\mathrm{i}$ is:

$$
L^{(i)}=\left({ }_{d 1} p_{x 1}^{j k}\right) \times\left({ }_{d 2} p_{x 2}^{k l}\right) .
$$

One observes that the formation of the likelihood is no trivial matter since there is no simple analytical expression for the higher order transition probabilities.

(3) If $\theta$ denotes the vector of parameters and $\hat{\theta}$ its maximum likelihood estimator, then standard theory tells that for a large sample of size $\mathrm{N}$ the MLE $\hat{\theta}$ is approximatively normally distributed with mean $\theta$ and covariance matrix $\mathrm{V}(\hat{\theta})$ :

$$
\begin{aligned}
& \lim _{\mathrm{N} \rightarrow \infty} \mathrm{E}(\hat{\theta})=\theta \\
& \mathrm{V}(\hat{\theta})=\frac{1}{N} \mathrm{I}^{-1}(\theta)
\end{aligned}
$$

where $\mathrm{I}(\theta)$ is the information matrix computed at the true value $\theta$. This implies the asymptotic normality of the estimates of the transition probabilities and health expectancies.

(4) The initial state was i, The proportion of outcome status was 1 (health) and 2 (disability).The prevalence ${ }_{t} W^{i 1}(x)$ among survivors at age $\mathrm{x}$ and in state 1 from a cohort of individuals in state $\mathrm{i}$ at age $\mathrm{x}-\mathrm{t}(\mathrm{t}$ years earlier) reads:

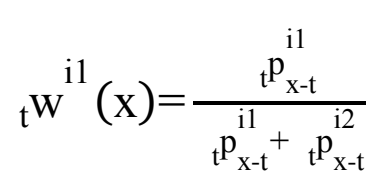

and the prevalence ${ }_{\mathrm{t}} \mathrm{W}^{\mathrm{i} 2}(\mathrm{x})$ :

$$
{ }_{t} W^{i 2}(x)=\frac{{ }_{t} p_{x-t}^{i 2}}{{ }_{t} p_{x-t}{ }_{x}+{ }_{t} p_{x-t}}
$$

(5) Calculate the incidence rate of individual ending status $\mathrm{j}$ (the stable disability rate in the state $\mathrm{j}$ )

$$
{ }_{y} p_{x}^{. j}(\theta)={ }_{y} p_{x}^{1 j}(\theta)+w^{2}(x, \theta)\left({ }_{y} p_{x}^{2 j}(\theta)-{ }_{y} p_{x}^{1 j}(\theta)\right)
$$


(6) Over the interval $(x, x+y)$, given the initial state $i$ at age $x$, with $y$ as the upper limit in the sums:

$$
\mathrm{y}_{\mathrm{x}}^{\mathrm{ij}}=\sum_{\mathrm{u}=1}^{\mathrm{y}} \mathrm{u}_{\mathrm{x}}^{\mathrm{ij}}
$$

(7) Total life expectancies respective of the initial state are:

$$
\mathrm{e}_{\mathrm{x}}^{\mathrm{i}}=\mathrm{e}_{\mathrm{x}}^{\mathrm{i} 1}+\mathrm{e}_{\mathrm{x}}^{\mathrm{i} 2}
$$

\section{Statistical analysis}

Firstly, SPSS17.0 software was used to describe the frequency of different health statuses of the elderly. It analyzed the distribution of health status by age, gender, occupation, education level, income level, and whether hungry or not. Secondly, $x^{2}$ test was used to explore the differences in socio-economic status of elderly people with or without starvation in childhood, taking $\alpha=0.05$ as the inspection standard. Thirdly, by IMaCh software, the multi-state life table method was used to measure the average life expectancy and healthy life expectancy of elderly people who have experienced starvation or not. Fourthly, the paired $t$ test was used to analyze the difference both of healthy life expectancy and healthy life expectancy proportion accounted for remaining life.

\section{Results}

\section{Data quality assessment}

Taking the sex-age structure of the elderly over 65 years in the sixth census in China as a reference, the data after weight adjustment of the cohort in the CLHLS database from 2008 to 2014 were compared. The results showed that the weighted adjusted data fitted well with the sixth census data of China (figure1). 


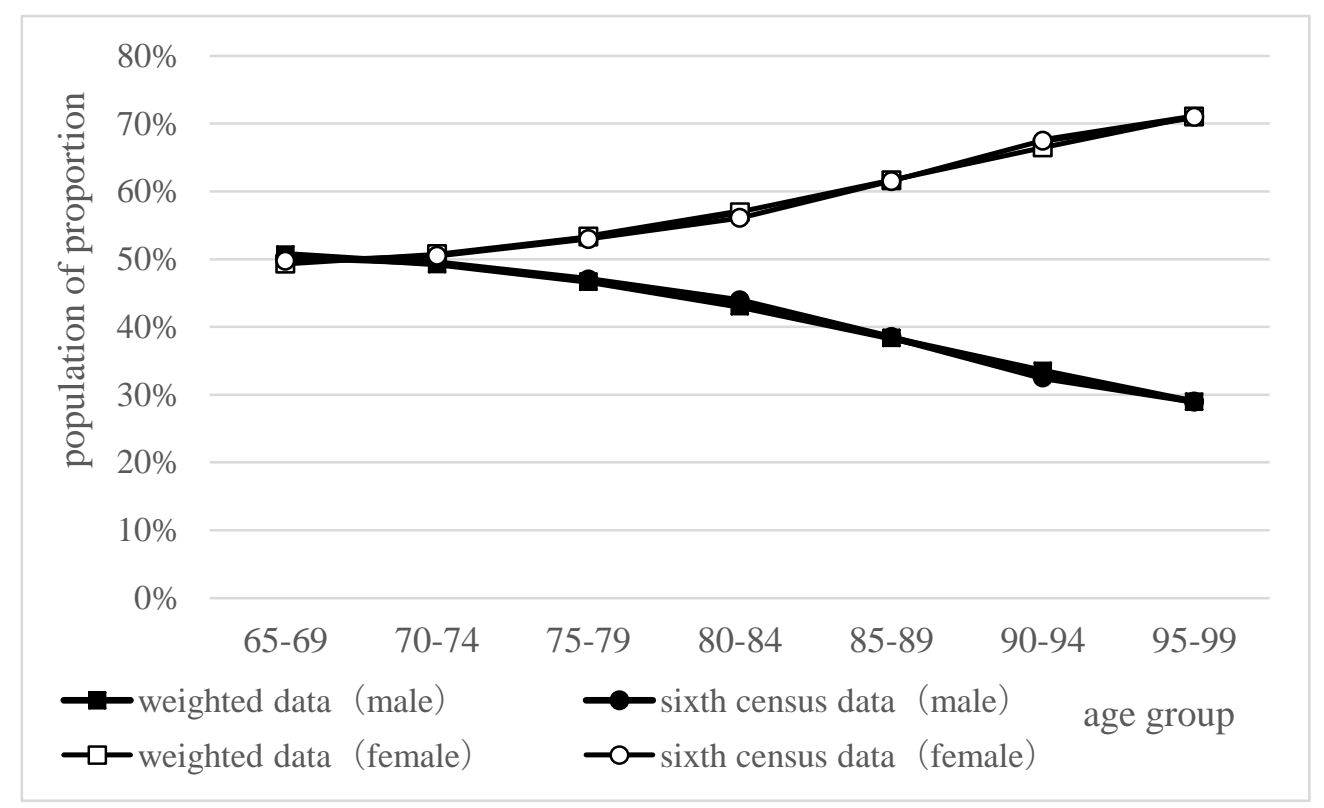

Figure 1 Comparison between the sixth census data of China and weighted survey data by sex-age structure

\section{Descriptive analysis}

With the weighted adjustment of the raw data, the baseline number in 2008 was 16,200. The remaining number in 2011 was 14,405 and the survivors in 2014 was 12,876 . In 2008, the proportion of elderly people under 80 years old accounted for $83.51 \%$. In 2011 and 2014, the proportion under 80 years old increased to $86.01 \%$ and $88.05 \%$ respectively. The proportion of female elderly was higher than $50 \%$, which was slightly higher than the male elderly. More than $60 \%$ of the elderly were farmers or unemployed; Over $80 \%$ were primary and lower in education, and lower- income, which presented a declining trend over time. The proportion of elderly people with hunger in 2008 was $66.1 \%$, rising to $65.9 \%$ in 2011 and $65.6 \%$ in 2014 respectively. From the perspective of health status, the proportion of healthy elderly decreased year by year during the follow-up period. Meanwhile the proportion of disabled and dead elderly showed an upward trend. (table1).

Table 1 Basic situation and health transition of the elderly

\begin{tabular}{lrrrrr}
\hline & 2008 Year & \multicolumn{2}{c}{ 2011Year } & \multicolumn{2}{c}{ 2014Year } \\
N & Proportion (\%) & N & Proportion (\%) & N & Proportion (\%) \\
\hline
\end{tabular}

Explanatory variable

Age group

$65-69$ 5590 34.51 5351 37.16 5097 39.59 


\begin{tabular}{|c|c|c|c|c|c|c|}
\hline $70-74$ & 4696 & 28.99 & 4266 & 29.62 & 3870 & 30.06 \\
\hline $75-79$ & 3242 & 20.01 & 2770 & 19.23 & 2369 & 18.40 \\
\hline $80-84$ & 1755 & 10.83 & 1401 & 9.73 & 1109 & 8.61 \\
\hline 85-89 & 696 & 4.30 & 495 & 3.44 & 352 & 2.73 \\
\hline $90-94$ & 184 & 1.14 & 106 & 0.74 & 66 & 0.51 \\
\hline $95-99$ & 37 & 0.23 & 16 & 0.11 & 13 & 0.10 \\
\hline \multicolumn{7}{|l|}{ gender } \\
\hline male & 7754 & 47.86 & 6780 & 47.08 & 5976 & 46.41 \\
\hline female & 8447 & 52.14 & 7622 & 52.93 & 6899 & 53.58 \\
\hline \multicolumn{7}{|l|}{ Occupation } \\
\hline \multicolumn{7}{|l|}{ famer or } \\
\hline unemployed & 10033 & 61.9 & 8764 & 65.1 & 7758 & 60.3 \\
\hline other & 5135 & 38.1 & 4695 & 34.9 & 4251 & 39.7 \\
\hline \multicolumn{7}{|c|}{ Education level } \\
\hline $\begin{array}{l}\text { Primary } \\
\text { schools and } \\
\text { below }\end{array}$ & 13234 & 81.69 & 11657 & 80.95 & 10349 & 80.37 \\
\hline $\begin{array}{l}\text { Above } \\
\text { primary } \\
\text { school }\end{array}$ & 2943 & 18.17 & 2721 & 18.89 & 2507 & 19.47 \\
\hline \multicolumn{7}{|l|}{ Economic } \\
\hline \multicolumn{7}{|l|}{ level } \\
\hline low income & 14115 & 87.1 & 12507 & 86.85 & 11136 & 86.49 \\
\hline high income & 2086 & 18.3 & 1876 & 13.03 & 1721 & 13.37 \\
\hline \multicolumn{7}{|l|}{ Starvation } \\
\hline yes & 10709 & 66.1 & 9489 & 65.9 & 8442 & 65.6 \\
\hline no & 5492 & 33.9 & 4912 & 34.1 & 4434 & 34.4 \\
\hline \multicolumn{7}{|c|}{ Health condition } \\
\hline health & 15405 & 95.09 & 10331 & 63.77 & 8024 & 49.53 \\
\hline disability & 796 & 4.91 & 1393 & 8.60 & 4627 & 28.56 \\
\hline death & 0 & 0 & 1800 & 11.11 & 3325 & 20.52 \\
\hline missing visits & 0 & 0 & 2677 & 16.52 & 225 & 1.39 \\
\hline
\end{tabular}

\section{Single factor analysis}

Explore the differences in the socioeconomic status of the two groups of elderly above. The results showed that there was a statistically significant difference in age, occupation, education level, and income level between the groups with or without starvation $(\mathrm{P}<0.05)$, but no statistical difference between genders $(\mathrm{P}>0.05)$. Specifically, the main features of the elderly with starvation experience were as follows: mainly over 80 years old $(74.3 \%)$, farmers or unemployed $(75.8 \%)$, lower 
education level with elementary schools and below (74.9\%), and mainly low-income (63.3\%). (Table 2).

\section{Risk transition probability}

\section{Health-disability and disability-health transition probability}

In general, the health-disability transition probability showed an upward trend with age, whether male or female, whereas the difference between the two groups gradually increased with age. On the contrary, the disability-health transition probability was decreasing with age for all the elderly

For the elderly males, the disability-health transition probability of the elderly who experienced starvation in childhood was lower than those without childhood starvation $(t=4.795, P<0.05)$, especially for those over 80 years old. The difference between the two groups gradually widened with age. However, as for health-disability transition probability, the elderly who experienced starvation in childhood were higher than those without starvation $(t=0.526, P>0.05)$.For the female elderly, the disability-health probability of the elderly with starvation in childhood was lower than those without childhood starvation $(t=3.279, P<0.05)$. Meanwhile, for the probability of health-disability transition, the situation of the two groups was just the opposite $(t=0.999, P>0.05)$.In addition, not only the health-disability but also the disability-health transition probability, displayed differences presented by age which show an increase among female seniors were greater than males (Figures 2 and 3). 


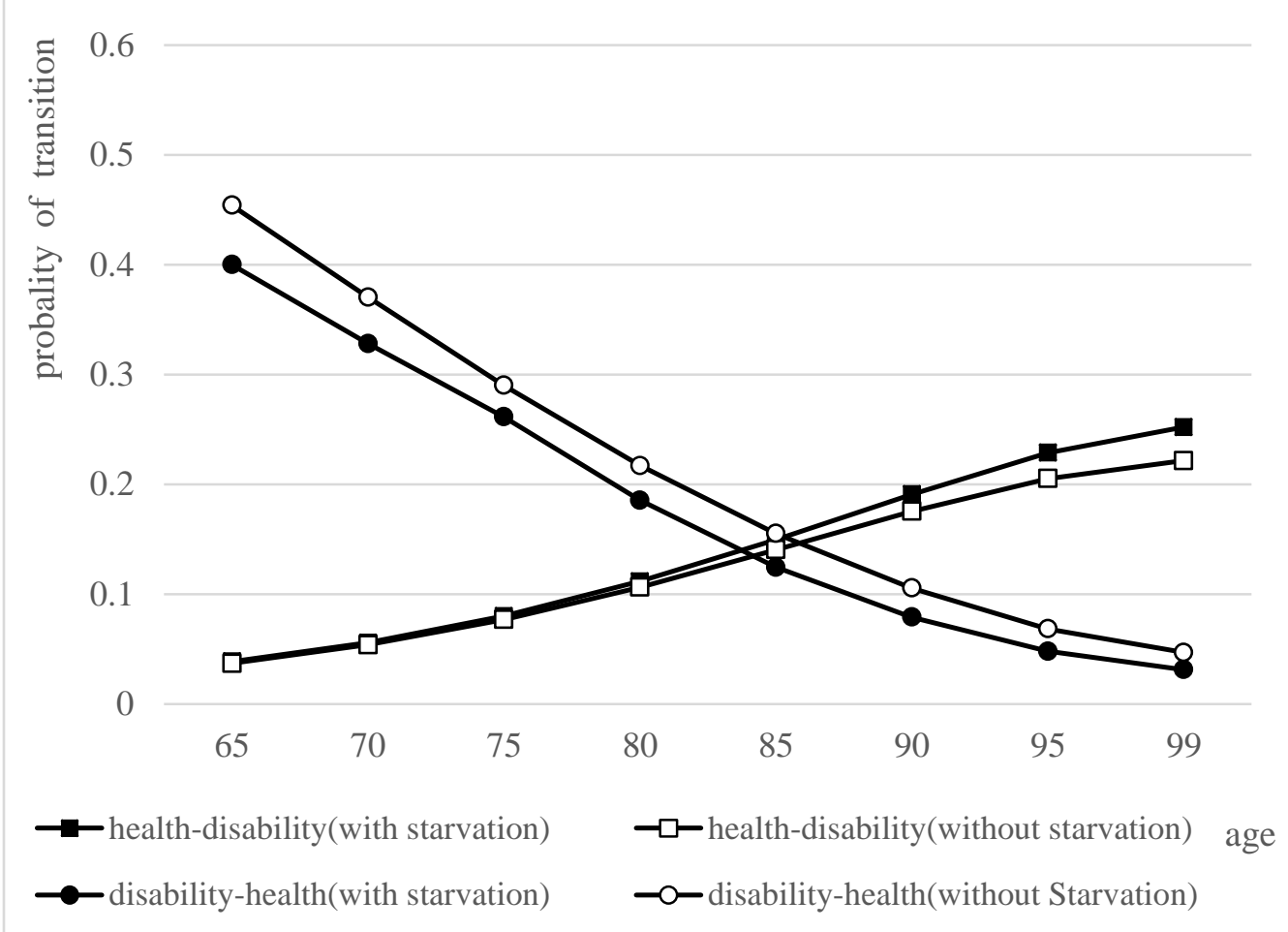

Figure 2 Comparison of the probability curves of disability and health transition among elderly males

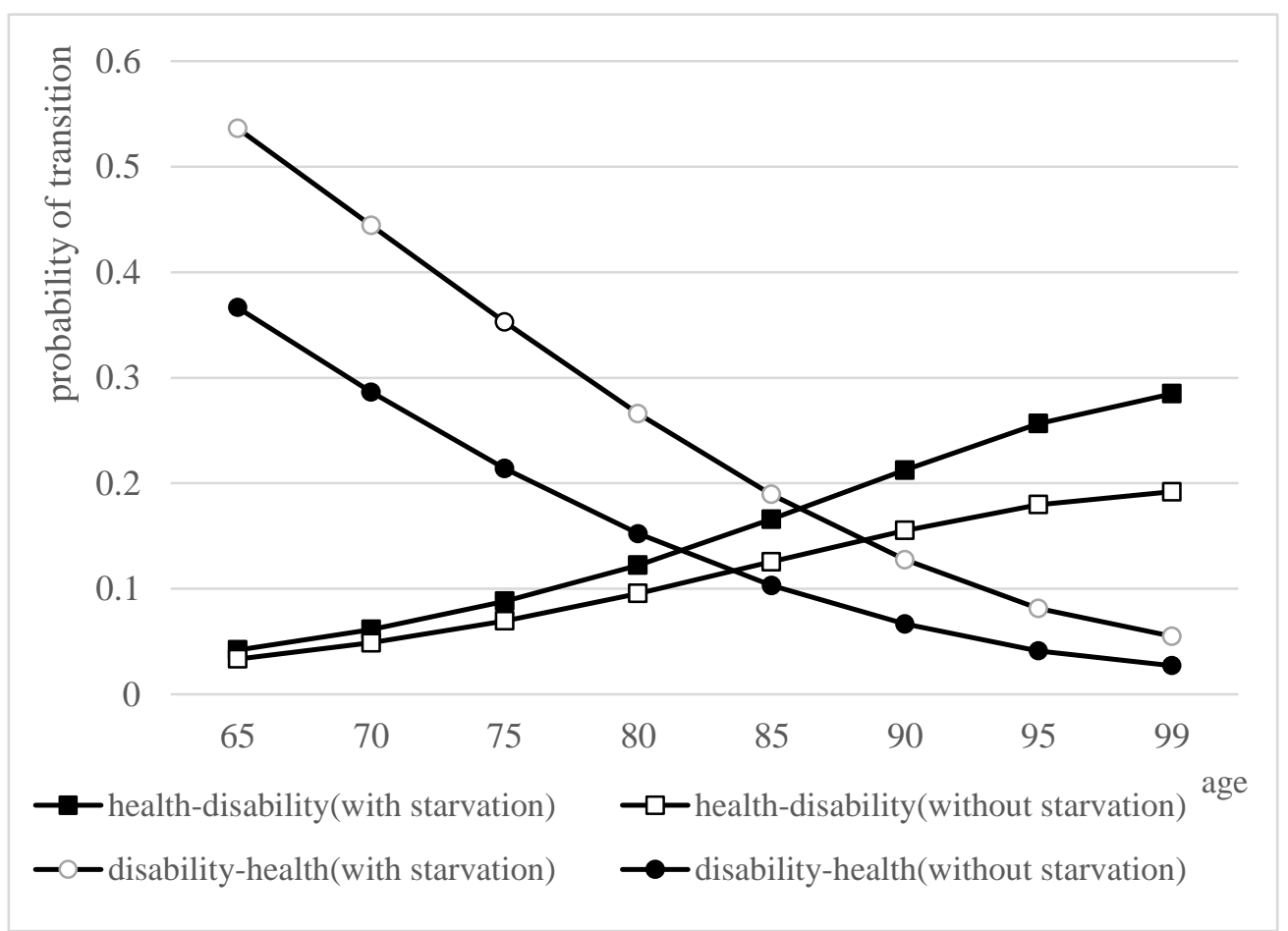

Figure3 Comparison of the probability curves of disability and health transition among elderly females

\section{Health-death and disability-death transition probability}


Overall, not only health-death but also disability-death transition probability of the elderly with or without starvation in childhood have both shown an upward trend, whereas the difference between the two groups gradually expanded with age. Specifically, for male elderly people who experienced starvation in childhood, the probability of disability-death transition $(t=8.140, P<0.05)$ and health-death transition probability $(t=2.079, P>0.05)$ were both higher than the elderly without experience of starvation. Similarly, as for the probability both of disability-death $(t=8.135, P<0.05)$ and health-death $(t=1.873, P>0.05)$, the female elderly who experienced starvation in childhood, were higher than those without experience of starvation. In addition, as for differences between starvation and or not, male elderly people were higher than female on disability-death transition probability, while female elderly people were greater than male ones on health-death transition probability (Figure 4 and Figure 5).

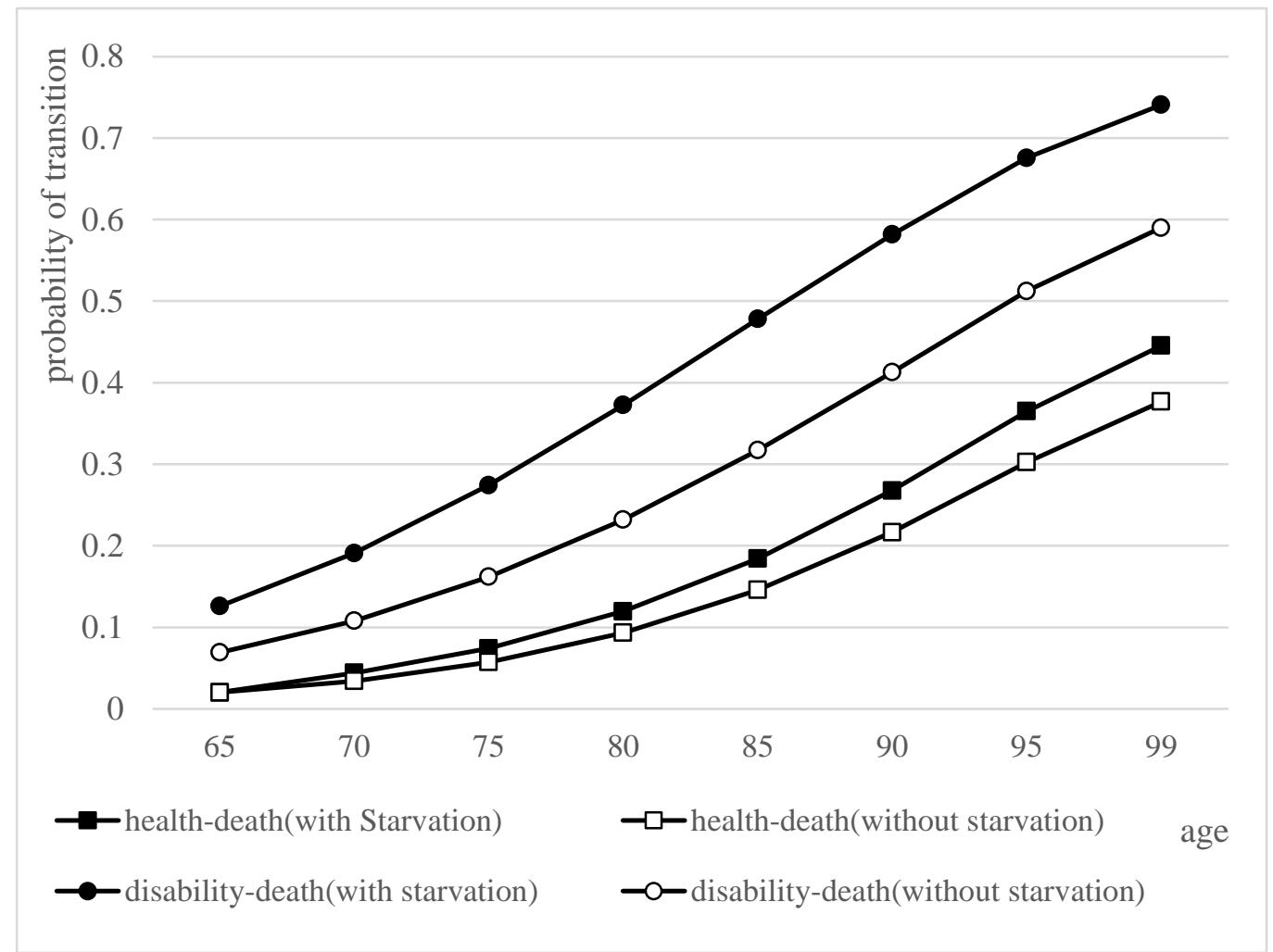

Figure 4 Comparison of health and death transition probability curves of male elderly 


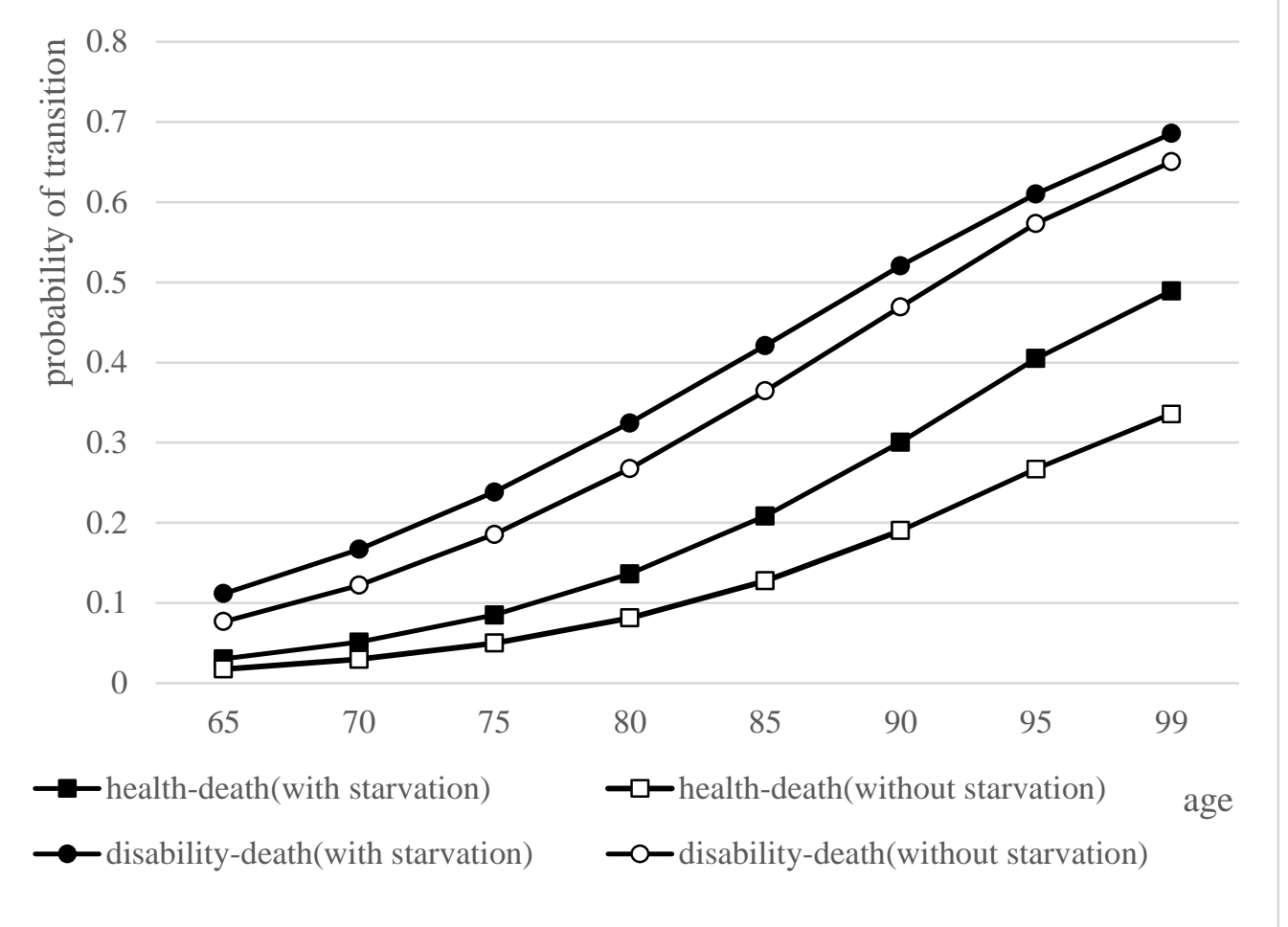

Figure 5 Comparison of health and death transition probability curves of female elderly

\section{Analysis of healthy life expectancy and its differences}

Overall, regardless of male and female, the elderly who experienced starvation in childhood were lower than the elderly without starvation experience on such indicators as the average life expectancy, healthy life expectancy and healthy life expectancy accounted for the remaining life, in which the difference between the two groups was gradually decreasing with age on the average life expectancy and the healthy life expectancy respectively.

For the elderly men, the healthy life expectancy of the elderly between 65-69 years old was $12.26 \pm 0.26$ years, while the average life expectancy was $14.36 \pm 0.27$ years, which meant that male elderly people between 65-69 years old were in a healthy state accounting for $85.30 \%$ of time. In the same age group, the healthy life expectancy of the elderly without hunger in childhood was $12.70 \pm 0.21$ years. Meanwhile the average life expectancy was $14.78 \pm 0.23$ years, indicating that $65-69$ year old males without hunger had $85.92 \%$ in a healthy state for the rest of their lives. The paired $t$ test found that the healthy life expectancy of the elderly without 
starvation in all age groups was higher than that of the elderly with starvation, with statistically significant difference $\quad(P<0.05)$, while the proportion of life expectancy (HLE/LE) of the elderly without starvation was also higher than that of elderly people with starvation. In which the difference was statistically significant $(P<0.05)$.

For the female elderly, the healthy life expectancy of those between 65-69 years-old with hunger experience was $14.06 \pm 0.30$ years, while the average life expectancy was $17.06 \pm 0.33$ years, which meant that the males between $65-59$ years-old with hunger had $82.30 \%$ in healthy state of the rest life. In the same age group, the healthy life expectancy of the elderly without hunger in childhood was $14.48 \pm 0.22$ years. Meanwhile the average life expectancy was $17.42 \pm 0.25$ years, indicating that the male elderly between $65-59$ years-old without hunger had $83.1 \%$ in a healthy state of living (table2).The paired $t$ test found that the healthy life expectancy of the elderly without starvation in all age groups was higher than that of the elderly with starvation, at which the difference was statistically significant $(P<0.05)$.The proportion (HLE/LE) of the elderly without starvation was also higher than that of elderly people who experienced starvation, at which the difference was statistically significant $(P<0.05)$.

Table 2 Comparison of healthy life expectancy among the elderly population( $(\mathbf{x} \pm \mathbf{s})$

\begin{tabular}{ccccccc}
\hline \multirow{2}{*}{$\begin{array}{c}\text { Age } \\
\text { group }\end{array}$} & \multicolumn{3}{c}{ With starvation } & \multicolumn{3}{c}{ Without starvation } \\
\cline { 2 - 7 } man & & HLE & HLE/LE $(\%)$ & LE & HLE & HLE/LE (\%) \\
$65-69$ & $14.36 \pm 0.27$ & $12.26 \pm 0.26$ & 85.3 & $14.78 \pm 0.23$ & $12.70 \pm 0.21$ & 85.92 \\
$70-74$ & $11.02 \pm 0.24$ & $9.03 \pm 0.23$ & 82.55 & $11.34 \pm 0.19$ & $9.39 \pm 0.18$ & 82.72 \\
$75-79$ & $8.23 \pm 0.21$ & $6.36 \pm 0.19$ & 77.19 & $8.46 \pm 0.17$ & $6.65 \pm 0.16$ & 78.54 \\
$80-84$ & $6.02 \pm 0.18$ & $4.30 \pm 0.17$ & 71.22 & $6.18 \pm 0.24$ & $4.53 \pm 0.16$ & 73.18 \\
$85-89$ & $4.38 \pm 0.16$ & $2.80 \pm 0.15$ & 63.68 & $4.48 \pm 0.14$ & $2.99 \pm 0.13$ & 66.48 \\
$90-94$ & $3.22 \pm 0.13$ & $1.77 \pm 0.15$ & 54.51 & $3.28 \pm 0.12$ & $1.92 \pm 0.13$ & 58.39 \\
$95-99$ & $2.44 \pm 0.11$ & $1.08 \pm 0.15$ & 44.03 & $2.47 \pm 0.09$ & $1.22 \pm 0.12$ & 49.08 \\
woman & & & & & & \\
$65-69$ & $17.06 \pm 0.33$ & $14.06 \pm 0.30$ & 82.3 & $17.42 \pm 0.25$ & $14.48 \pm 0.22$ & 83.1 \\
$70-74$ & $13.38 \pm 0.30$ & $10.51 \pm 0.27$ & 78.43 & $13.65 \pm 0.22$ & $10.87 \pm 0.20$ & 79.56 \\
$75-79$ & $10.19 \pm 0.38$ & $7.50 \pm 0.27$ & 73.42 & $10.37 \pm 0.20$ & $7.79 \pm 0.18$ & 74.99 \\
$80-84$ & $7.58 \pm 0.24$ & $5.09 \pm 0.21$ & 67.02 & $7.67 \pm 0.19$ & $5.32 \pm 0.16$ & 69.21 \\
$85-89$ & $5.55 \pm 0.22$ & $3.29 \pm 0.18$ & 59.16 & $5.59 \pm 0.17$ & $3.48 \pm 0.15$ & 62.14 \\
$90-94$ & $4.07 \pm 0.19$ & $2.04 \pm 0.16$ & 49.96 & $4.07 \pm 0.15$ & $2.20 \pm 0.14$ & 53.87
\end{tabular}


Note: (1LE: average life expectancy; (2)HLE: healthy life expectancy; (3HLE/LE: healthy life expectancy accounted for the remaining life

\section{Discussion}

The life course provides an important theoretical perspective for a comprehensive analysis of the health status of the elderly. The results of this study showed that the experience of starvation in childhood had a negative cumulative effect on the health in old age, which was related to the social and historical environment of the research group. The target group was born in 1908-1942 during was a special historical period of social transformation, political turmoil and material deprivation. During the time, many elderly people had experienced starvation before the age of $12^{[15]}$. Some scholars have studied the long-term negative effects of "great famine of China" on the health of famine-experienced people ${ }^{[16-17]}$. However, as a rare historical event, the "Great Famine" has serious, extreme, and transient characteristics, which conclusions drawn have certain limitations in terms of external validity. In contrast, the adverse effects of the childhood starvation on health in this paper are more typical and more universal.

The experience of starving in childhood affects the socioeconomic status of adulthood, which in turn affects the health outcomes of the elderly. The results of this study showed that the elderly who have experienced starvation in childhood were mainly farmers or unemployed $(75.8 \%)$, mostly primary school and below in education $(74.9 \%)$, and lower income level $(63.3 \%)$. The literature that examined the long-term effects of fetal or childhood health as independent variables found that chronically poor health or malnutrition in childhood had a significant negative impact on the years of education during adulthood ${ }^{[18]}$. Qing He and Yuan Yan analyzed the data of CHNS to show that the overall health status during childhood had a significant positive effect on adult income ${ }^{[19]}$. Specifically, people with low socioeconomic status usually have cumulative disadvantages in terms of work environment, access to medical services, and health risks, which can affect their availability of health resources and health protection capacity ${ }^{[20]}$.

The multi-state transition probability is the basis for measuring healthy life expectancy. When calculating the healthy life expectancy, the transitions between different multiple health states and the death risk could be taken to consideration, in 
which the result is closer to the health level of the crowd. This study found that regardless of the elderly with or without starvation in childhood, the transition probabilities showed an upward trend on such as health-disability, health-death, and disability-death with age, while the probability of disability-health showed a downward trend. The elderly people with starvation in all age groups were lower than those who did not experience starvation in childhood. This result reflects that the impact of childhood nutrition on the health of people depends on the degree of hunger in childhood. Disability is a reversible state that can return to health or it can lead to death. It means that we should pay more attention to the problem of malnutrition in childhood, earlier detection, earlier intervention and earlier treatment, to not cause lasting adverse health effects.

The elderly who experienced starvation in childhood are higher than those without hunger in the three indicators, such as average life expectancy, healthy life expectancy, and healthy life expectancy, which result is closely related to the transition probability. Older people who experienced starvation in childhood had a higher probability of health-disability, but the probability of disability-health recovery was relatively low. Therefore, the probability of disability-health recovery is the key indicator to explain the difference between the two groups above. The lower health recovery rate reflects lower utilization of medical services, on which the social status of education and economic status affects the conditions and quality of medical service utilization ${ }^{[21]}$.Therefore, good education and economic conditions can not only increase their utilization of health resources, but also increase awareness of preventive health care, which can effectively reduce the possibility of disability and increase the rate of disability-health recovery. The elderly without childhood hunger have obvious advantages in this respect.

The policy enlightenment brought by the research is that the improvement of the material life improvement level in China under rapid economic growth in recent years, and the support of the social security system cannot completely offset negative effects on the health level of the elderly from malnutrition of childhood starvation experience. Therefore, the government should strengthen nutrition and health interventions for poor children, and effectively improve the nutrition and health status of children in poverty-stricken areas and families through the implementation of nutrition improvement programs for pre-school children. At the same time, health investment 
on children is an important prerequisite for the elderly people bonus. At present, the delayed retirement age has taken shape in China, but the smooth implementation of this policy depends largely on the health of the elderly. The research in this article shows that the health problems of the elderly population should be considered from the perspective of life course, and policy makers should have a forward-looking awareness to strengthen the nutritional improvement and health promotion of vulnerable groups in the early life.

\section{Limitations}

First, due to the limitations of $\mathrm{IMaCH}$ model, if all the individual and family socio-economic status and environmental variables were included as control variables, it was very difficult to calculate. Therefore, this paper only took gender and age as the basic variable, and the current income level as the control variable in the model. The second is that if the nutritional status in childhood is too bad and leads to death, then these people will not appear in the sample of 2008-2014. Therefore, the estimates obtained from the sample used in this article may have survivor bias, which will underestimate the impact of childhood starvation experience on the health of the elderly.

\section{Conclusion}

The negative impact of childhood starvation on health through life course till old age has a persistent negative cumulative effect on the quantity and quality of life for the elderly population. This study meant that for the social groups with poor early nutritional status, the upward mobility of adult social class and the improvement of material living conditions can not completely offset the negative effects of early hunger experience. Therefore, in order to achieve healthy aging, government decision makers should have a sense of foresight and take systematic intervention of all factors affecting health from early stage of life.

\section{Acknowledgements}

The authors would like to give great gratitude to the participants. Thanks to the data support provided by the Chinese Longitudinal Healthy Longevity Survey (CLHLS) research group.

\section{Author Contributions}

Conceived and designed the study: Bingyi Wu. Gathered and Analyzed the data:Huiling Dong,Contributed materials/analysis tools: Bingyi Wu. Wrote the paper: 
Huiling Dong. Reviewed/edited/approved: Qunhong Wu.All authors read and approved the final manuscript.

\section{Funding}

The study was funded by Chinese National Social Science Foundation (grant number:18BRK013). The funders had no role in the study design, data collection and analysis, decision to publish, or preparation of the manuscript.

\section{Availability of data and materials}

The data used in this study are are openly available in the Peking University Open Research Data at:

https://opendata.pku.edu.cn/dataset.xhtml?persistentId=doi:10.18170/DVN/XRV2WN

\section{Ethics approval and consent to participate}

Ethical approval for this study was obtained from the "Weifang Medical University Life Science Ethics Committee", and written informed consent was obtained from all participants.

\section{Consent for publication}

Not applicable.

\section{Competing interests}

The authors have declared that no competing interests exist.

\section{Author details}

${ }^{1}$ Department of Public Health, Weifang Medical University, No. 7166 Baotong West Street, 261053 Weifang, Shandong, China. ${ }^{2}$ Department of Management, Weifang Medical University, No. 7166 Baotong West Street, 261053 Weifang, Shandong, China. ${ }^{3}$ Department of Public Health and Management, Harbin Medical University, No. 157, Health Road, Nangang District, Harbin,150081, China.

\section{References}

1. Xin Meng,Nancy Qian. The Long Run Health and Economic Consequences of Famine on Survivors: Evidence from China's Great Famine. CEPR Discussion Papers. 2006;11,1-65.https://www.researchgate.net/publication/4759894.

2. Habibi E, Sajedi F, Afzali H M, et al. Early Childhood Development and Iranian Parents' Knowledge: A Qualitative Study. International Journal of Preventive Medicine.2017;1,84. Doi/10.4103/ijpvm.IJPVM_159_17. 
3. WHO; http://www.unscn.org/layout/modules/resources/files/ rwns5.pdf.

4. Almond D,Currie J.Human Capital Development before Age Five. Handbook of Labor Economics.2011;4,1315-1486.Doi/10.1016/S0169-7218(11)02413-0

5. Akbulut-Yuksel M. War during childhood: The long run effects of warfare on health. Journal of Health Economics. 2017;53,139.Doi/10.1016/j.jhealeco. 2017;02.005

6. Neelsen S, Stratman T. Effects of prenatal and early life malnutrition: Evidence from the Greek famine. Social Science Electronic Publishing. 2011;30,479-488.Doi /10.1016/j.jhealeco.2011.03.001

7. Schellenberg $\mathrm{J}$ A, Victora C G, Mushi A. Inequities among the very poor: health care for children in rural southern Tanzania. Lancet. 2003;361,561-566. Doi /10.1016/s0140-6736(03)12515-9

8. Chen Y, Zhou L A. The long-term health and economic consequences of the 1959-1961 famine in China. Journal of health economics.2007;4,659-681.

9. Zaninotto P, Head J, Steptoe A. Behavioural risk factors and healthy life expectancy: evidence from two longitudinal studies of ageing in England and the US. Scientific Reports.2020;1,1-9.Doi /10.1038/s41598-020-63843-6.

10. Pedersen J, Bjorner J B. Worklife expectancy in a cohort of Danish employees aged 55-65? years-comparing a multi-state Cox proportional hazard approach with conventional multi-state life tables. BMC Public Health. 2017;1,879. Doi /10.1186/s12889-017-4890-7.

11. Zhang WJ, Wei M. Estimation of disability level and time of the elderly in China: an analysis based on combined data. Population study,2015;39,3-14.

12. Huang RT. On the concept of Child and its Age definition in Forensic Identification Standard. the Fifth National Forensic academic Exchange Conference. 1996.

13. Shanshan Qin. An important analysis of children's mental health care in different ages. Contemporary medicine.2014;24,159-159.

14. Lievre, A., Brouard, N., \& Heathcote, C. The estimation of health expectancies from cross-longitudinal surveys. Mathematical population studies. 2003;4,211-248.Doi /10.1080/713644739 
15. Shi ZL, Wu ZM. In the early years, the long-term impact on health inequality: the history of life and the double-cumulative disadvantage. Sociological research. 2018;195,170-196.

16. Xu H, Li L, Zhang Z. Is natural experiment a cure? Re-examining the long-term health effects of China's 1959-1961 famine. Social Science \& Medicine.2016;148, 110-122. Doi /10.1016/j.socscimed.2015.11.028.

17. Gabriele Doblhammer-Reiter, Gerard J. Long-Term Effects of Famine on Life Expectancy: A Re-Analysis of the Great Finnish Famine of 1866-1868. Population Studies.2011;67,309-322(14). Doi /10.1080/00324728.2013.809140.

18. Cole M A, Neumayer E. The impact of poor health on total factor productivity: an empirical investigation. Journal of Development Studies. 2006;42,918-938. Doi /10.2139/ssrn.482654.

19. He Qing, Yuan Yan. The intertemporal income effect of health and nutritional status on Adulthood childhood. Economic Review. 2014;2, 52-64.

20. Brown J, Michie S, Geraghty A W. Internet-based intervention for smoking cessation in people with low and high socioeconomic status: a randomized controlled trial. The Lancet Respiratory Medicine.2014;2,997-1006. Doi /10.1016/S2213-2600(14)70195-X.

21. Yang J J, Yoon H S, Lee S A. Metabolic syndrome and sex-specific socio-economic disparities in childhood and adulthood: The Korea National Health and Nutrition Examination Surveys. Diabetic Medicine.2014;31,1399-1409. https://doi.org/10.1111/dme.12525. 